\title{
Antioxidant and Antiapoptotic effect of aqueous extract of Pueraria tuberosa (Roxb. Ex Willd.) DC. On streptozotocin-induced diabetic nephropathy in rats
}

\author{
Rashmi Shukla', Somanshu Banerjee ${ }^{2}$ and Yamini B. Tripathi ${ }^{*}$
}

\begin{abstract}
Background: Oxidative stress and renal apoptosis play a significant role in the progression of diabetic nephropathy. The tubers of Pueraria tuberosa (Roxb. ex Willd.) DC. has been traditionally used as anti-ageing and health promotive tonic. The purpose of this study was to investigate its nephroprotective effect and mechanism via antioxidant and antiapoptotic potential in Streptozotocin-induced diabetic nephropathy (DN) in rats.

Methods: The chemical composition of aqueous extract of Pueraria tuberosa (PTY-2r) was analyzed by gas chromatography-mass spectrometry (GC-MS). Diabetes was induced by intraperitoneal injection of streptozotocin (STZ) ( $55 \mathrm{mg} / \mathrm{kg}$ body weight) in rats. After 60 days, the rats were randomly divided into 3 groups ( $n=6 /$ each group), namely DN control (DN) group-2, DN rats treated with PTY-2r at the dose of 50 mg/100 g, group-3 and 100 mg/100 g, group-4 p.o. for 20 days. The normal rats were chosen as a normal control (NC) group-1. PTY-2r was orally given to the rats for 20 days. Reactive oxygen species (ROS), lipid peroxidation (LPO) and the activity of ROS-scavenging enzymes - superoxide dismutase (SOD), catalase (CAT) \& glutathione peroxidase (GPX) were determined in the kidney tissue of DN rats. The expression of apoptosis-related proteins was measured by immunofluorescence.

Results: GC-MS analysis of PTY-2r indicated the presence of 37 compounds among them 5-Hydroxymethylfurfural (17.80\%), 2,3-dihydro-3,5-dihydroxy-6-methyl-4H-pyran-4-one (17.03\%), n-Hexadecanoic acid (5.18\%) and 9-Octadecenoic acid (Z) (6.69\%) were found in the higher amount. A significant increase in ROS and LPO was observed along with the decreased activity of antioxidant enzymes, responsible for oxidative stress in the kidney of DN rats. Since, high oxidative stress induces apoptosis in target cells, as shown by significantly decreased expression of Bcl-2 along with increased expression of Bax, active Caspase-3 \& cleaved PARP-1 in DN control rats, suggesting apoptosis. The PTY-2r treatment significantly raised the activity of antioxidant enzymes, suppressed oxidative stress and apoptosis thus, prevented urinary albumin excretion in a dose-dependent manner.
\end{abstract}

Conclusions: The findings suggest that PTY-2r exerted the nephroprotective potential against STZ induced DN rats via suppressing oxidative stress and apoptosis due to the presence of different bioactive compounds.

Keywords: Pueraria tuberosa, Diabetic nephropathy, Antioxidant, Antiapoptotic, Nephroprotective, GC-MS

\footnotetext{
*Correspondence: yaminiok@yahoo.com; yaminimedchem17bhu@gmail.com

${ }^{1}$ Department of Medicinal Chemistry, Institute of Medical Sciences, Banaras

Hindu University, Varanasi 221005, India

Full list of author information is available at the end of the article
}

(c) The Author(s). 2018 Open Access This article is distributed under the terms of the Creative Commons Attribution 4.0 International License (http://creativecommons.org/licenses/by/4.0/), which permits unrestricted use, distribution, and reproduction in any medium, provided you give appropriate credit to the original author(s) and the source, provide a link to the Creative Commons license, and indicate if changes were made. The Creative Commons Public Domain Dedication waiver (http://creativecommons.org/publicdomain/zero/1.0/) applies to the data made available in this article, unless otherwise stated. 


\section{Background}

Diabetic nephropathy (DN) is one of the major complications of diabetes and the major leading cause of endstage renal disease (ESRD). It is a progressive disease, assessed by a time-dependent rise in urinary albumin excretion and decline in renal functions [1]. In diabetic condition, hyperglycemia promotes oxidative stress and induced the excess generation of ROS, which plays a critical role in the pathogenesis of DN [2]. Increased production of ROS and oxidative stress (OS) causes enzyme inactivation, cell membrane damage, alteration in endogenous antioxidant gene expression and apoptosis [3]. In the kidney tissue, the high generation of ROS leads to renal apoptosis, resulting in glomerular barrier dysfunction and increased albumin excretion [4]. Renal diseases, particularly diabetic nephropathy has shown the features of apoptotic cell death [5-8]. Apoptosis may also cause podocyte loss in diabetic nephropathy and hence may lead to increased excretion of urinary albumin. These studies strongly suggested that ROSmediated renal apoptosis is an early mechanism leading to DN. Thus, ROS-mediated renal apoptosis becomes a promising target for the development of nephroprotective drugs to prevent the initiation and progression of $\mathrm{DN}$. The current therapeutics for $\mathrm{DN}$ is mainly antihypertensive drug such as angiotensin-converting enzyme (ACE) inhibitor and Angiotensin II receptor blockers (ARBs). Although for the treatment of DN, some drugs have been developed but they have not proven to be effective in clinical trials for clinical use [9]. Due to the limitation of allopathic drugs, the herbal medicines are being explored either as drugs or food supplements. The crude form of herbal medicines is a natural cocktail of phytochemicals and synergistically acts on different signaling pathways to get a better response $[10,11]$.

Pueraria tuberosa (PT) (Roxb. ex Willd.) DC. is a perennial herb commonly known as "vidarikanda" and distributed in the tropical parts of India [12]. The plant's tuber is widely used in ethnomedicine as well as in traditional systems of medicine, particularly in Ayurveda. Its traditional clinical use in Ayurveda indicates its antiageing and health-promotive potential (named as "Rasayana drugs") [13]. Its tubers are rich in flavonoids and isoflavones e.g., puerarin (8.31\%), daidzein (1. $70 \%)$ and genistein (1.37\%), tuberosin,, 4-methoxypuerarin, quercetin, hydroxytuberosone, biochanin $\mathrm{A}$, biochanin $\mathrm{B}$, irisolidon, glycoside (C-glycoside 4',6-diacetyl), puerarone, tectoridin and robinin [14, 15].

We have already reported its anti-inflammatory [16], antioxidant [17] and anti-diabetic properties [18, 19]. Studies also reported its anti-fertility [20], immunomodulatory and nootropic activity [21]. But not enough reports are available regarding its effect on chronic kidney disease like DN. In our earlier investigation, we reported that the aqueous extract of PT plays a beneficial role in reducing the STZ induced DN by inhibiting the accumulation of ECM via restoration of MMP-9 expression [18] and also effective in attenuation of hypoxia mediated DN by suppressing the expression of HIF- $1 \alpha$ and VEGF [22]. In the current study, the bioactive constituents of PTY-2r were analyzed by GC-MS and elucidation of the mechanistic pathway through which PTY-2r ameliorates diabetic nephropathy in rats.

\section{Methods \\ Chemicals}

The PVDF membranes (catalog no. IPVH 20200, Millipore), mouse monoclonal $\beta$-actin (A2228) Horseradish peroxidase conjugated anti-rabbit IgG (A1949), STZ (S0130) were purchased from Sigma-Aldrich, St Louis, USA. Rabbit polyclonal Bcl-2 (N-19): SC492, rabbit polyclonal Bax (SC6236), were purchased from Santa Cruz Biotechnology, Inc. Cleaved PARP-1 ([E51], ab32064), rabbit anti-mouse IgG $\mathrm{H} \& \mathrm{~L}$ (conjugated with FITC-green fluorescence, ab6724) and goat anti-rabbit IgG H\&L (conjugated with TRITC-red, ab6718) were purchased from Abcam, USA. Active Caspase-3 (Asp175) purchased from Cell Signaling Technology, Inc. Prestained protein molecular weight marker was obtained from Hi-media Pvt. Ltd., Kolkata, India. All biochemical were of analytical grade. Biochemical kits were purchased from Accurex Biomedical Pvt. Ltd., Biosar, Thane.

\section{Extract preparation and gas chromatography- mass spectroscopy (GC-MS)}

PT tubers were purchased from local market, authentication and extraction was done as described earlier [22]. In brief the tuber of Pueraria tuberosa (Roxb. ex Willd.) DC. was identified by Prof. K.N. Dwivedi, Department of DravyaGuna, Institute of Medical Science, Banaras Hindu University and also compared with the preserved sample in the herbarium of Department of Medicinal Chemistry Institute of Medical Science, Banaras Hindu University, (voucher no. YBT/MC/12/1-2007). $50 \mathrm{~g}$ of coarse powder of PT was boiled with 5volume of water. Volume reduced to $14^{\text {th }}$ and filtered. Filtered extract was washed with hexane in separating funnel then aqueous part (PTY-2r) was collected and concentrated by a rotatory evaporator and lyophilized. It stored at $-20{ }^{\circ} \mathrm{C}$ until use. The chemical compositions of PTY-2r were analyzed by GC-MS.

GC-MS analysis was carried out by using Shimadzu QP-2010 Plus with Thermal Desorption System TD 20 with quadrupole detector; the injection temperature was $260{ }^{\circ} \mathrm{C}$ in split mode. The pressure was $77.5 \mathrm{kPa}$. The oven temperature was initially kept at $70{ }^{\circ} \mathrm{C}$ with holds time of $2.00 \mathrm{~min}$, and then raised to $250{ }^{\circ} \mathrm{C}$ at the rate of $7{ }^{\circ} \mathrm{C} / 2$ min then $280{ }^{\circ} \mathrm{C}$ at the rate of $10{ }^{\circ} \mathrm{C}$ with hold 
time of $28.00 \mathrm{~min}$. The ion source and interface temperature was $230{ }^{\circ} \mathrm{C}$ and $270{ }^{\circ} \mathrm{C}$ respectively. The compounds were identified by comparing mass spectra with those of NIST (WILLEY8.LIB) mass spectral library.

\section{Preliminary quantitative chemical analysis}

Total phenolic content was estimated by folin-ciocalteu assay [23] and expressed in terms of $\mu \mathrm{g}$ gallic acid equivalent (GAE/mg). Gallic acid was used as a standard solution. Briefly, $0.5 \mathrm{ml}$ of sample was mixed with 1 . $0 \mathrm{~mL}$ of $1 \mathrm{~N}$ of Folin-Ciocalteu reagent. The contents were mixed and allowed to stand for $5 \mathrm{~min}$ at room temperature. Next, $1 \mathrm{~mL}$ of $75 \%$ sodium carbonate solution was added, followed by distilled water. Solutions were mixed and allowed to stand at room temperature for $15 \mathrm{~min}$, and then absorbance was recorded at $760 \mathrm{~nm}$ against distil water as blank.

Total flavonoids content was measured by using aluminum chloride (2\%) [24] in which it was mixed with solution of test samples. Absorbance measured at $415 \mathrm{~nm}$ (Elico SL177) after 10 min against a blank sample consisting of $1.0 \mathrm{~mL}$ of sample solution and $1.0 \mathrm{ml}$ of methanol without aluminum chloride. The total flavonoids content was determined by using a standard curve of quercetin at $0-150 \mu \mathrm{g} / \mathrm{mL}$. The average of three readings were used and then expressed in $\mu \mathrm{g}$ of quercetin equivalent to flavones per mg extract.

Tannin content was estimated as described by Van Baren [25] with slight modification. Tannic acid used as standard solution. $1 \mathrm{~mL}$ of extract was mixed with $2 \mathrm{ml}$ of $0.1 \mathrm{M} \mathrm{FeCl} 3$ in $0.1 \mathrm{~N} \mathrm{HCl}$ and $0.008 \mathrm{M}$ potassium ferrocyanide. The absorbance was measured at $720 \mathrm{~nm}$ within $10 \mathrm{~min}$. Using spectrophotometer (Elico SL177). Tannin content was expressed in terms of $\mu \mathrm{g}$ tannic acid equivalent (TAE) /mg.

\section{Animal experiment detail and induction of DN}

The male rats of Charles Foster strain (100-120 g) were injected with STZ (55 mg/kg body weight, freshly prepared in citrate buffer of $\mathrm{pH} 4.5$, i.p.) after the overnight fasting. The rats with a blood glucose level higher than $17 \mathrm{mmol} / \mathrm{l}$ were considered as diabetic [26]. DN was induced by maintaining the persistent hyperglycemia for 60 days in rats. The periodic checks of renal function tests, diabetes and urine albumin was done upto 60 days after every 10 days. The rats with positive albuminuria were considered as diabetic nephropathy bearing rats and they were randomly divided into different groups.

\section{Treatment protocol}

The normal rats were chosen as a normal control $(\mathrm{NC}, n=$ 6, group-1), STZ induced DN control rats, $(\mathrm{DN}, \mathrm{n}=6$, group-2), STZ induced DN rats, treated with PTY-2r (DN + PTY-2r, $50 \mathrm{mg} / 100$ g body weight, $n=6$, group-3) \& STZ induced DN rats, treated with PTY-2r (DN + PTY-2r, $100 \mathrm{mg} / 100 \mathrm{~g}$ body weight, $\mathrm{n}=6$, group-4). The rats of group- 1 and group- 2 were given drug vector. After 20 days of treatment, all the rats were sacrificed by giving anesthesia with $1 \%$ pentobarbital (i.p. $45 \mathrm{mg} / \mathrm{kg}$ body weight) and the left kidneys were snap-frozen in liquid nitrogen and stored at $-80{ }^{\circ} \mathrm{C}$ for biochemical estimation. The right kidneys were fixed in $10 \%$ neutral formalin for immunofluorescence studies. The experiment was conducted in accordance with institutional practice and within the framework of the revised Animals (Scientific procedures) Act of 2002 of the Government of India on Animal Welfare.

\section{Urinary albumin excretion (UAE)}

Rats were placed into the metabolic cages (Vishnu traders, Roorkee-247,667, Uttrakhand, India) for $24 \mathrm{~h}$ urine collections at the end of the experiment. A pinch of thymol was added to the urine collection beaker to prevent the microbial growth. Estimation of UAE was done byAfinion ${ }^{\mathrm{mm}} \mathrm{AS} 100$ Analyzer in Parul Pathology, Lanka Varanasi, India.

\section{Total ROS level}

The total ROS generation in the fresh homogenate of tissue was assessed by using the method of Bejma et al. 2000 [27] with slight modification [28]. Briefly, the homogenate was diluted in PBS to obtain a concentration of $25 \mu \mathrm{g}$ tissue protein $/ \mathrm{ml}$. The reaction mixture containing diluted homogenate and $10 \mu \mathrm{l}$ of 2' 7 ' - dichloro dihydro fluorescein diacetate (DCFH-DA) $(10 \mu \mathrm{M})$ was incubated for $15 \mathrm{~min}$ at room temperature. After $30 \mathrm{~min}$ of further incubation, the conversion of DCFH-DA to the fluorescent product DCF was measured by using a spectrofluorometer with excitation at $484 \mathrm{~nm}$ and emission at $530 \mathrm{~nm}$.

\section{Lipid peroxidation assay (LPO)}

The level of lipid peroxides was measured as thiobarbituric acid reacting substance (TBARS) and expressed as equivalent to malondialdehyde (MDA) by using 1,1,3,3-tetramethoxypropane (TEP) as standard in kidney homogenate [29]. It was expressed in terms of $\mu \mathrm{mol} / \mathrm{mg}$ protein.

\section{Antioxidant enzyme activity in kidney tissue}

The kidney tissue homogenate $(10 \% w / v)$, was prepared in $0.1 \mathrm{M}$ potassium phosphate buffer $(\mathrm{pH} 7)$ containing a protease inhibitor. It was centrifuged at $10,000 \mathrm{~g}$ for 20 min at $4{ }^{\circ} \mathrm{C}$ and the clear supernatant was utilized for assay of superoxide dismutase (SOD) [30], Catalase (CAT) [31], glutathione peroxidase (GPx) [32].

\section{Superoxide dismutase (SOD)}

Activity was determined in terms of inhibition of reduction of nitro blue tetrazolium (NBT) in the presence of riboflavin as described [30] with slight modification [33]. 
Table 1 Quantitative estimation of phytochemicals present in PTY-2r

\begin{tabular}{llll}
\hline $\begin{array}{l}\text { Fraction } \\
\text { of PT }\end{array}$ & $\begin{array}{l}\text { Total phenolic } \\
\text { content }(\mu \mathrm{g} \\
\text { of GAE/mg) }\end{array}$ & $\begin{array}{l}\text { Total flavone } \\
\text { content }(\mu \mathrm{g} \text { of } \\
\text { QE/ mg) }\end{array}$ & $\begin{array}{l}\text { Total tannin } \\
\text { content }(\mu \mathrm{g} \\
\text { of TAE/ mg) }\end{array}$ \\
\hline PTY-2r & $150 \pm 9.56$ & $72 \pm 3.54$ & $5.9 \pm 2.67$ \\
\hline
\end{tabular}

Values are means of three independent determinations \pm standard deviation (SD)

In brief, each $3 \mathrm{ml}$ of reaction mixture contained $0.01 \mathrm{M}$ phosphate buffer (PBS, pH 7.8), $130 \mathrm{mM}$ methionine, 0 . $5 \mathrm{mM}$ EDTA, $0.75 \mathrm{mM}$ NBT, $60 \mu \mathrm{M}$ riboflavin and $0.5 \mathrm{ml}$ of kidney homogenate. It was kept in front of a fluorescent light and after $6 \mathrm{~min}$ absorbance was taken at $560 \mathrm{~nm}$. The SOD activity was expressed as $\mathrm{U} / \mathrm{mg}$ protein.

\section{Catalase activity (CAT)}

Was assessed by Aebi's method [31] by measuring the rate of decomposition of $\mathrm{H}_{2} \mathrm{O}_{2}$ at $240 \mathrm{~nm}$ as reported earlier [34]. In brief, the reaction mixture contained $1.9 \mathrm{ml}$ of $50 \mathrm{mM}$ PBS (pH 7.0) and diluted kidney homogenate to make volume $2 \mathrm{ml}$. The reaction was initiated by the addition of $30 \mathrm{mM}$ hydrogen peroxide $\left(\mathrm{H}_{2} \mathrm{O}_{2}\right)$ and absorbance was measured at $240 \mathrm{~nm}$ for $2-3 \mathrm{~min}$. The catalase activity expressed in terms of $\mathrm{U} / \mathrm{mg}$ protein.

\section{Glutathion peroxidase (GPX) activity}

Was assayed as described by Mantha et al. [32]. In brief, $50 \mu \mathrm{l}$ of sample was added to a reaction mix containing $398 \mu \mathrm{l}$ of $50 \mathrm{mM}$ phosphate buffer, $2 \mu \mathrm{l}$ of $1 \mathrm{mM}$ EDTA, $10 \mu \mathrm{l}$ of $1 \mathrm{mM}$ sodium azide, $500 \mu \mathrm{l}$ of $0.5 \mathrm{mM} \mathrm{NADPH}$, $40 \mu \mathrm{l}$ of $0.2 \mathrm{mM} \mathrm{GSH}$ and $1 \mathrm{U}$ glutathione reductase and allowed to equilibrate at room temperature. Then, the reaction was initiated by addition of $100 \mathrm{mM} \mathrm{H} \mathrm{H}_{2} \mathrm{O}_{2}$. The absorbance measured kinetically at $340 \mathrm{~nm}$. The
GPx activity was expressed as $\mu$ mol of oxidized NADPH oxidized to $\mathrm{NADP}^{+}$per min per mg of protein.

Immunofluorescence for Bax, Bcl-2, active Caspase-3, \& cleaved PARP-1 in the kidney sections using confocal microscopy

The kidney tissue was fixed in $10 \%$ formalin, embedded in paraffin wax and $5 \mu \mathrm{m}$ thick sections were cut by using the rotatory microtome, Lieca RM2125 RT (Leica Biosystems Nussloch GmbH, Nussloch, Germany) and the Immunofluorescence of Bax, Bcl-2, active Caspase-3 and cleaved PARP-1 was performed in a two-step procedure as mentioned elsewhere [35]. Briefly, kidney sections were deparaffinized in xylene and rehydrated in graded series of alcohol. Heat induced antigen retrieval was performed using $1 \mathrm{M}$ citrate buffer $(\mathrm{pH}$ 6) in a microwave oven at $1000 \mathrm{~W}$ (1-2 min). After treating with blocking solution for $2 \mathrm{~h}$ at room temperature (5\% HIGS- Heat Inactivated Goat serum), different sections were incubated with different antibodies Bax(dilution1: 25), Bcl-2(dilution 1:50), active Caspase-3 (dilution 1:50) and cleaved PARP-1 (dilution 1:20) for $24 \mathrm{~h}$ in humid chamber. Sections were then washed with TBS (3 X 5 min.) and incubated with rabbit anti-mouse IgG H\&L (conjugated with FITC) and goat anti-rabbit IgG H\&L (conjugated with TRITC), (1:200) for $3 \mathrm{~h}$. at room temperature in dark. After incubation, sections were again washed with TBST(tris bufferes saline with tween20) (3 X $5 \mathrm{~min}$.) and two drops of the fluorescent media (0.5\% N-propyl gallate $+20 \mathrm{mM}$ Tris in $90 \%$ glycerol + DAPI) were applied on the sections. Coverslips were applied and then sealed with nail polish after ensuring the spread of the mounting media over all the sections without any bubble formation). Nuclei were counterstained with DAPI $(1 \mu \mathrm{g} / 10 \mathrm{ml}$ PBS).

Table 2 Major compounds identified in PTY-2r through GC-MS analysis

\begin{tabular}{|c|c|c|c|c|c|c|c|c|}
\hline S.no & R.time & Name & Area & Area\% & Formula & $\begin{array}{l}\text { Molar } \\
\text { mass } \\
\text { (g/mol) }\end{array}$ & Structure & Reported activity \\
\hline 1. & 8.623 & $\begin{array}{l}\text { 2,3-dihydro-3,5-dihydroxy- } \\
\text { 6-methyl-4H-pyran-4-one }\end{array}$ & $23,642,509$ & 17.03 & $\mathrm{C}_{6} \mathrm{H}_{8} \mathrm{O}_{4}$ & 144.126 & & $\begin{array}{l}\text { Antioxidant, antifungal [41]. } \\
\text { anti-inflammatory, anti-proliferative } \\
\text { \& pro-apoptotic [56] }\end{array}$ \\
\hline 2. & 10.263 & 5-Hydroxymethylfurfural & $24,722,467$ & 17.80 & $\mathrm{C}_{6} \mathrm{H}_{6} \mathrm{O}_{3}$ & 126.111 & $H$ & Anti-apoptotic $[51,52]$ \\
\hline 3. & 22.631 & n-Hexadecanoic acid & $7,188,212$ & 5.18 & $\mathrm{C}_{16} \mathrm{H}_{32} \mathrm{O}_{2}$ & 256.43 & & $\begin{array}{l}\text { Antioxidant and Bactericidal activity } \\
\text { [57, 58], Anti-inflammatory, } \\
\text { antimicrobial [59]. }\end{array}$ \\
\hline 4. & 23.675 & 9-Octadecenoic acid (Z)- & 201,065 & 6.69 & $\mathrm{C}_{14} \mathrm{H}_{26} \mathrm{O}_{2}$ & 226.36 & & $\begin{array}{l}\text { Anticancer, Anti-inflammatory, } \\
5 \text {-alpha } \\
\text { reductase inhibitor }[58,60]\end{array}$ \\
\hline
\end{tabular}




\section{Image analysis}

Immunofluorescence of Bcl-2, Bax, active Caspase-3 and cleaved PARP-1 in the kidney section of all the groups were observed under a Zeiss LSM510 Meta laser-scanning confocal microscope with a Plan-Apo 20.0×, 1.4- NA oil immersion objective and the images were collected using LSM 510 Meta software in same magnification and stored in TIFF (tag index figure format) files. Integrated optical density (IOD) of all images were measured and analyzed using Image J software (Image J 1.48, National Institute of Health, Bethesda, MA, USA) and signal intensity of immune-positive signals were measured as mentioned previously [35]. The IOD values (arbitrary unit) were averaged (four sections per kidney and 6 kidneys per group) to determine the signal density. Based on the signal intensity, the term intense, moderate and weak were applied.

\section{Statistical analysis}

All data were presented as the mean $\pm \mathrm{SD}$. One-way ANOVA followed by post-Hoc analysis (Dunnett's T3) was used to determine the significance among different groups. A $p$-value of $<0.05$ was considered as significant and data was analyzed using the statistical software package, Statistical Analysis System (SPSS Statistics 20.0, IBM, Armonk, NY, USA).

\section{Results}

Preliminary quantitation of chemical constituents in PTY-2r Preliminary phytochemical analysis revealed that the PTY-2r rich in total phenols, flavonoids and tannins, as a major constituents as shown in Table 1. Total phenolic content was found to be $150 \pm 9.56 \mu \mathrm{g} / \mathrm{mg}$ of Gallic acid equivalent and total tannin i.e. polyphenolic content was

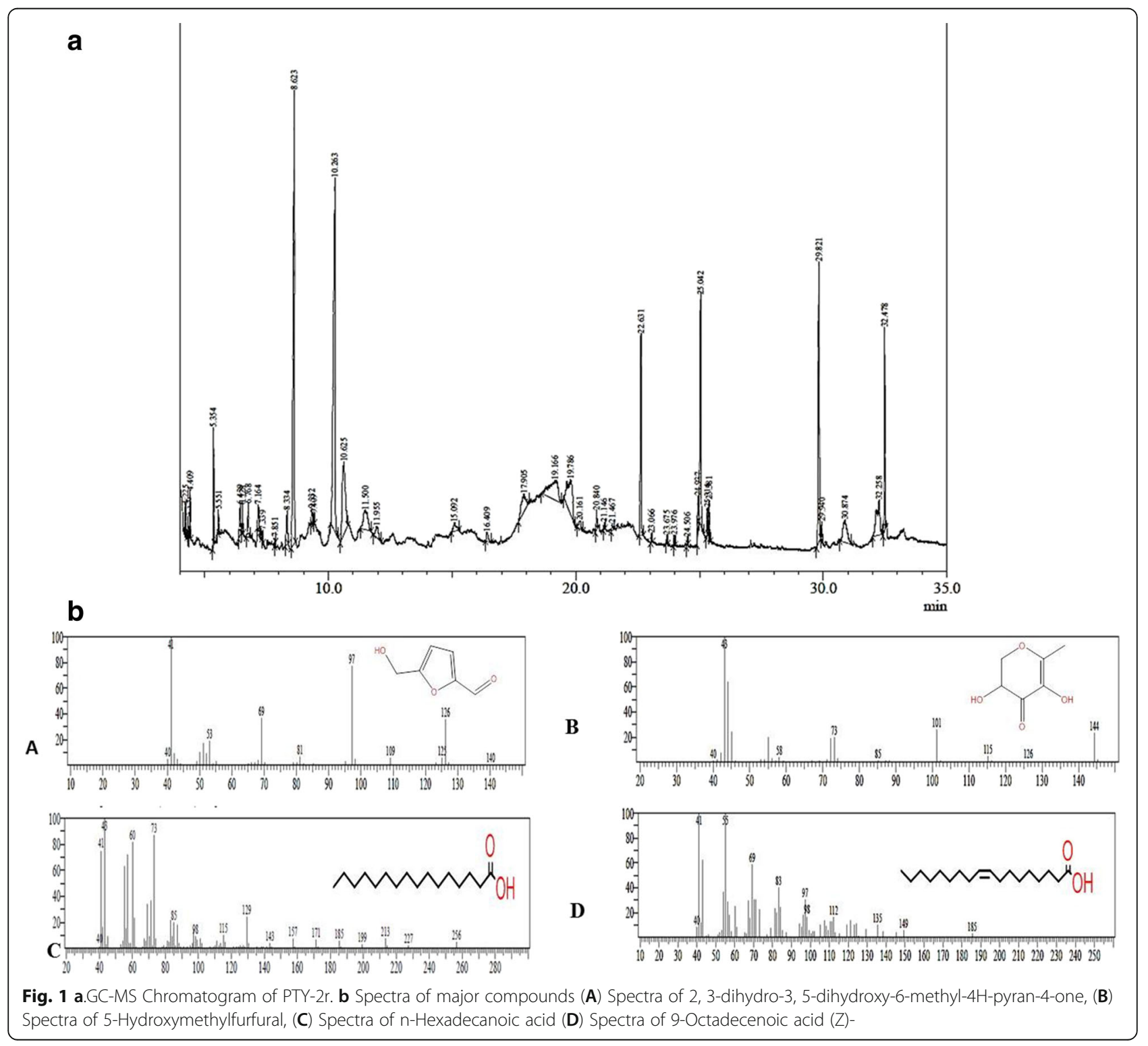


observed to be $72 \pm 3.54 \mu \mathrm{g} / \mathrm{mg}$ of tannic acid equivalent. Total flavonoid content was estimated $15.9 \pm 2.67 \mu \mathrm{g} / \mathrm{mg}$ of quercetin equivalent.

\section{GC-MS analysis}

Total 37compounds were identified in the PTY-2r are shown in Additional file 1: Table S1 along with their structure and reported activities. The major constituents present in the extract were 5-Hydroxymethylfurfural (17. $80 \%$ ) which is reported as antiapoptotic, 2, 3-dihydro-3, 5dihydroxy-6-methyl-4H-pyran-4-one (17.08\%) reported as strong antioxidant, Other minor constituents are 9Octadecenoic acid (Z) (6.69\%) and n-Hexadecanoic acid $(5.18 \%)$ are also reported as antioxidant, as shown in Table 2 with their reported activity. Fig. 1 shows the GCMS chromatogram and the spectra of major compounds.

\section{Effect of PTY-2r the overproduction of free radicals}

In the renal tissue of $\mathrm{DN}$ rats, high oxidative stress was observed, as ROS \& LPO content were significantly increased, when compared to NC rats $(p<0.001)$. However, the PTY-2r treatment significantly reversed these changes and decreased the ROS production in dose-dependent manner (Fig. 2a). Overproduction of ROS was further supported by the high degree of lipid peroxides, which was measured as thiobarbituric reactive substances (TBARS). The malondialdehyde (MDA) is the main product of LPO, which increases during oxidative stress, MDA level was significantly increased in DN control rats compared to NC group, while PTY-2r treatment significantly decreased its concentration in dose-dependent manner (Fig. 2b).
The higher dose $(100 \mathrm{mg})$ was more effective than low dose (50 mg).

Effect of PTY-2r on the activity of antioxidant enzymes Since, there was increased production of ROS which suppressed the activity of antioxidant enzymes, so we further checked the activity of antioxidant enzymes (SOD, CAT \&GPx) in kidney tissue of all the groups. As shown in Fig. 3, the activity of the antioxidant enzymes was significantly decreased in $\mathrm{DN}$ rats compared to $\mathrm{NC}$, while 20 days of PTY-2r treatment significantly restores the activity of these enzymes in a dose-dependent manner but the effect was more significant in higher dose.

\section{Effect of PTY-2r on renal apoptosis by using immunofluorescence}

As the generation of ROS is responsible for renal apoptosis, thus we further examined the expression of antiapoptotic protein i.e. Bcl-2 \& pro-apoptotic i.e. Bax, active Caspase-3 and cleaved PARP-1 in the kidney tissue of all the groups. Biochemical analysis showed that the $100 \mathrm{mg} /$ $100 \mathrm{~g}$ dose of PTY-2r is more efficient, thus we further checked the effect of PTY-2r (100 mg/100 g) on immunoreactivity of apoptotic proteins in the kidney of DN rats by immunofluorescence. As shown by immunofluorescence of kidney sections (Fig. 4-a, b, c \& d), the DN rats showed significantly intense immunoreactivity of Bax (2174.16 $\pm 385.499, p<0.001)$, active Caspase-3 $(1527.2 \pm$ 83.2, $\mathrm{p}<0.001)$ \& cleaved PARP-1 $(2144.5 \pm 212.04, \mathrm{p}<0$. 001) while weak immunoreactivity was found for Bcl-2 $(177.9 \pm 30.7, \mathrm{p}<0.001)$ in glomerulus, indicating more

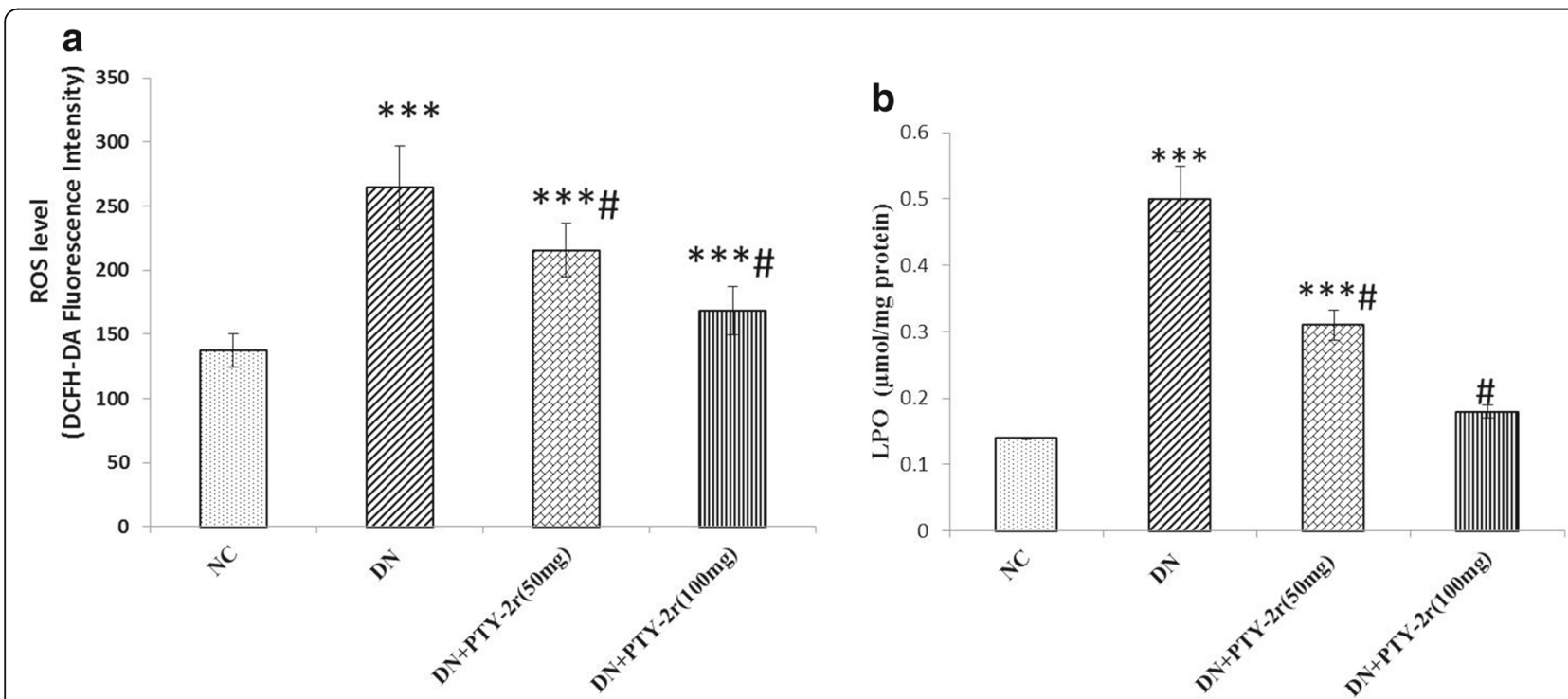

Fig. 2 Effects of PTY-2r on Overproduction of Free Radicals: (a) ROS measured by DCFH-DA fluorescence intensity (b) Concentration of LPO in the kidney of NC, DN control, DN + PTY-2r (50 mg/100 g) and DN + PTY-2r (100 mg/100 g). Data are presented in mean \pm SD ( $n=6$ in each group). ${ }^{* * *} p<0.001$, compared with group-1, $\# p<0.001$ compared with group-2 


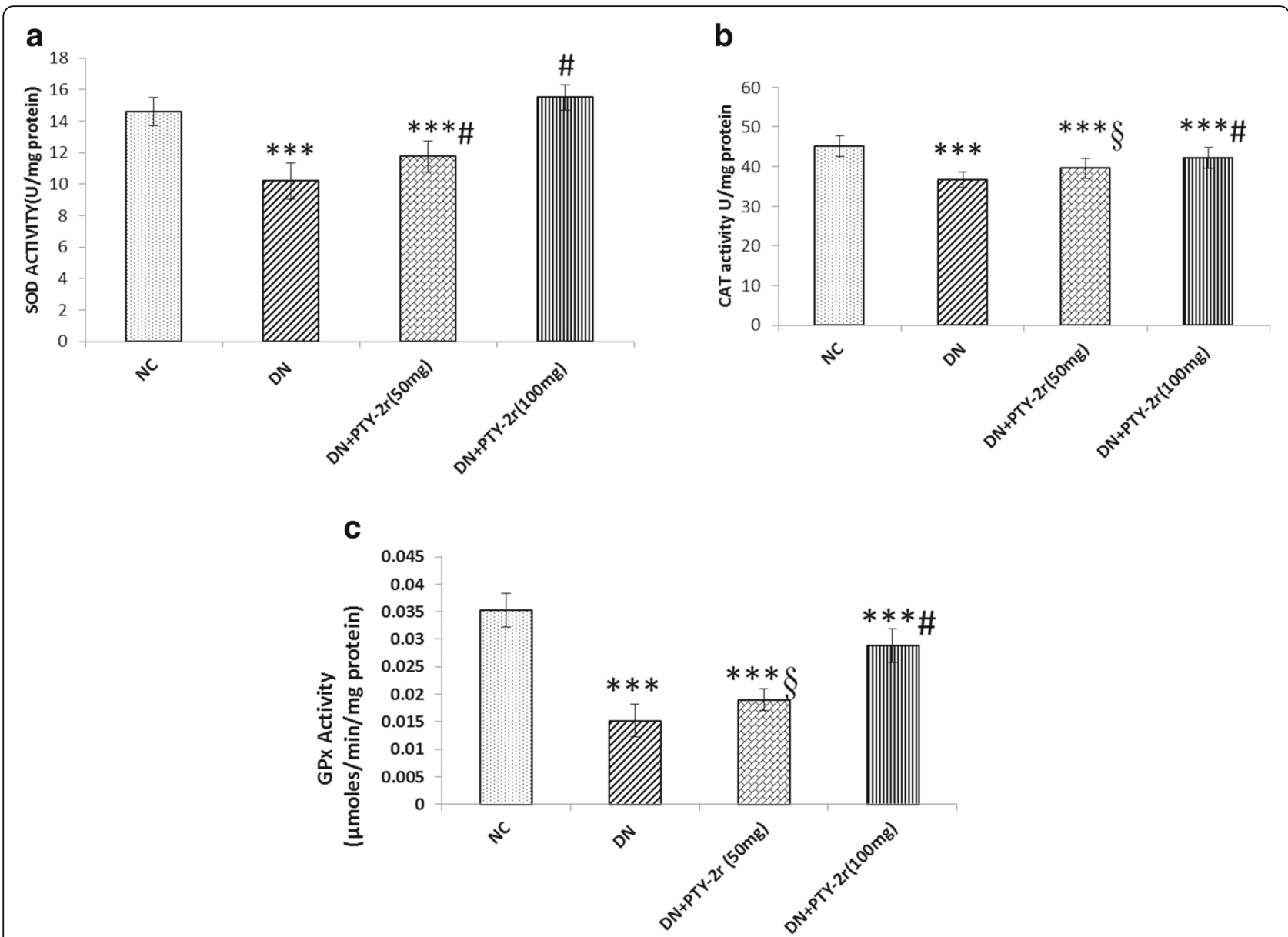

Fig. 3 Effects of PTY-2r on Activity of Antioxidant Enzymes through Biochemical Estimation: (a) SOD (b) CAT (c) GPx in NC, DN control, DN + PTY$\operatorname{2r}(50 \mathrm{mg} / 100 \mathrm{~g})$ and DN + PTY-2r (100 mg/100 g). Data are presented in mean \pm SD ( $n=6$ in each group). ${ }^{* *} \mathrm{p}<0.001$ compared with group-1; ${ }^{\#} p<0.001,{ }^{\$} p<0.05$, compared with group-2

degree of renal apoptosis. The treatment of PTY-2r significantly reversed the immunoreactivity of all the protein as compared to $\mathrm{DN}$ rat.

\section{Effect of PTY-2r on urinary albumin excretion}

The urinary albumin excretion was measured, which showed a significant increase in DN rats compared with NC. The treatment with PTY-2r significantly reduced the albumin content in urine in a dose-dependent manner. The percent change in group-3 $(50 \mathrm{mg})$ was $26.9 \%$ and 55\%in group-4 (100 mg) (Fig. 5).

\section{Discussion}

Several studies reported the direct involvement of oxidative stress in the pathogenesis of DN [2, 36, 37]. Excess generation of ROS leads to the severe cellular oxidative damage viz. LPO derivatives and this weaken the antioxidant machinery system (SOD, CAT, and GPx) $[37,38]$ in the kidney of DN rats. Kidney cells are more vulnerable to
ROS mediated oxidative damage because of a high rate of oxygen consumptions [39]. Previously, we have reported that the STZ induced DN rats had clinical characteristics of increase proteinuria, urea and creatinine along with decreased creatinine clearance showed successful induction of DN and PTY-2r treatment significantly ameliorates these changes in a dose-dependent manner [22]. The present study is a continuous exploration of nephroprotective effect and underlying mechanism of PTY-2r in STZ induced DN rats. We observed the significant increase in oxidative stress markers i.e. ROS \& LPO along with decreased ROS scavenging enzymes (SOD, CAT \& GPx) in the kidney of DN rats. This is in accordance with the earlier reports, where inverse correlations between oxidative stress and activity of antioxidant enzymes have been reported [40]. The PTY-2r treatment significantly suppressed the increased production of ROS and LPO as compared to DN control rats and significantly raised the activity of antioxidant enzymes, in a dose-dependent 


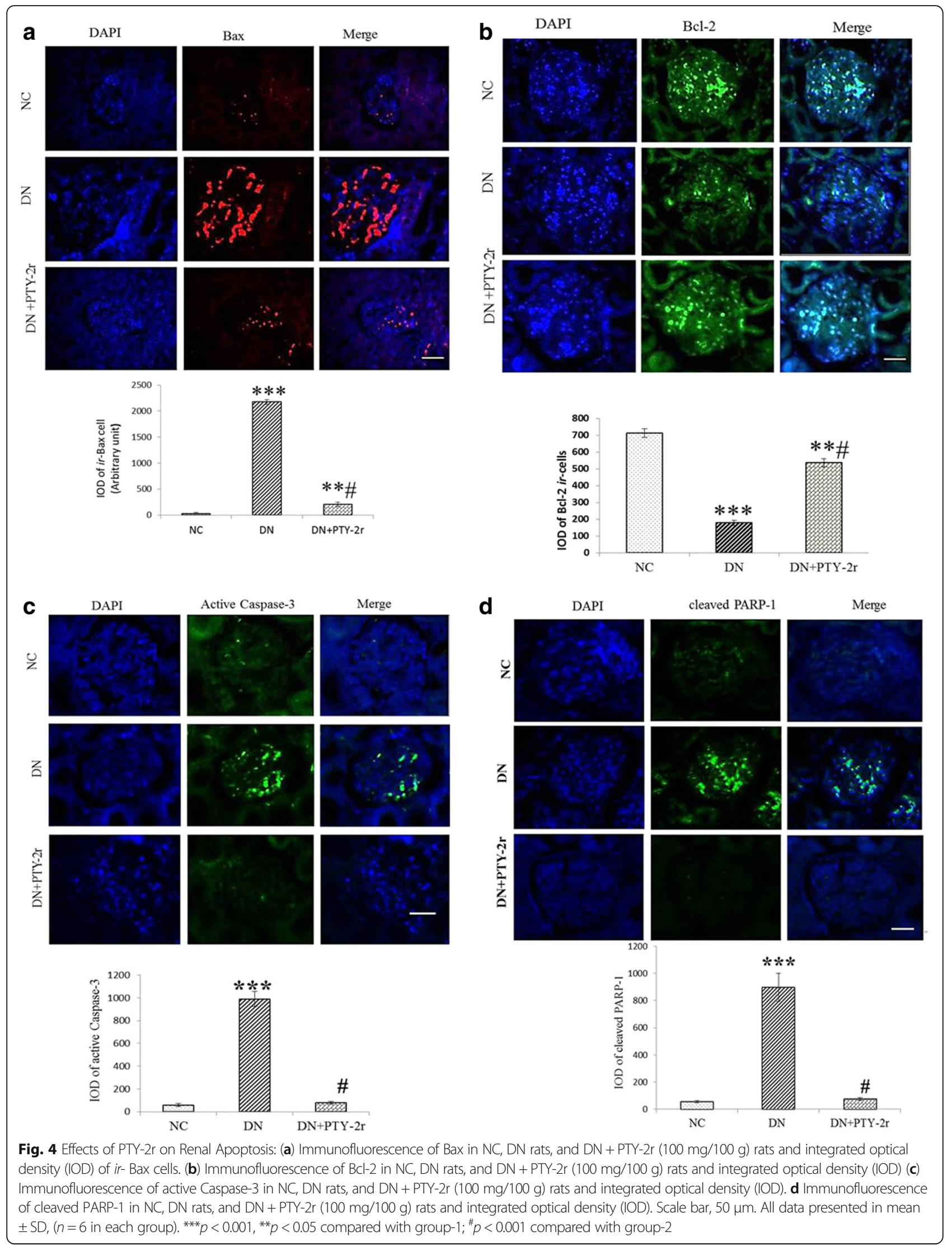




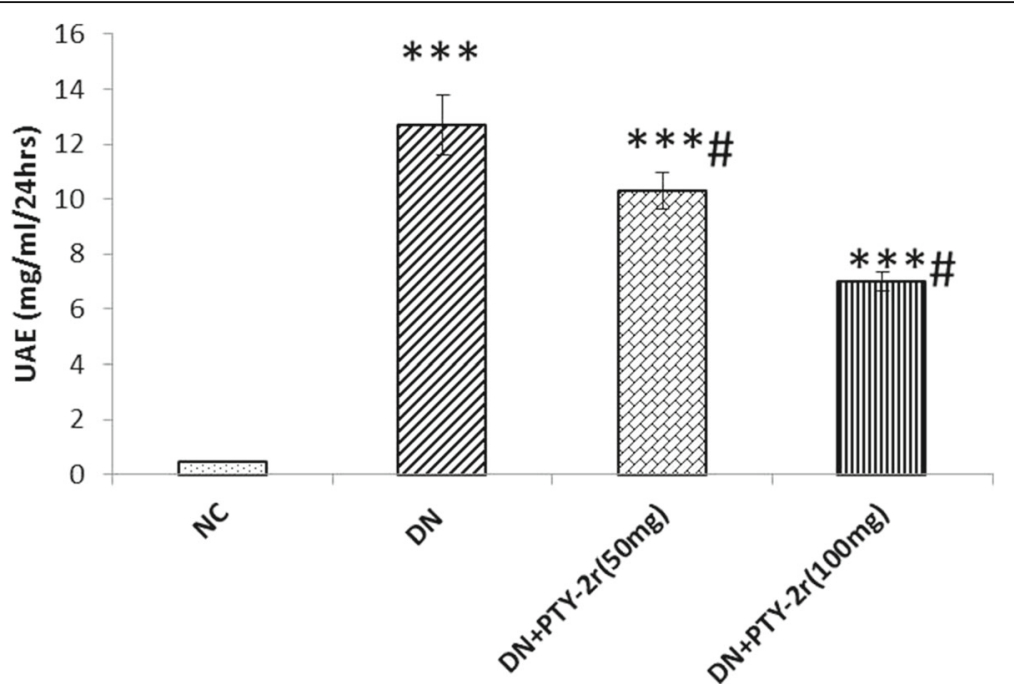

Fig. 5 Effects of PTY-2r on urinary albumin excretion (UAE): NC, DN control, DN + PTY-2r (50 mg/100 g) and DN + PTY-2r (100 mg/100 g). Data are presented in mean \pm SD ( $n=6$ in each group). ${ }^{* * *} p<0.001$ compared with group-1; $\# p<0.001$ compared with group-2

manner, suggesting a significant antioxidant potential of PTY-2r. This antioxidant property of PTY-2r could be due to presence 2,3-dihydro-3,5-dihydroxy-6-methyl-4H-pyran-4-one (17.08\%) and $n$ - hexadecanoic acid which are identified through GC-MS analysis were reported as a strong antioxidant [41]. PTY-2r extract also rich in flavone, flavonoids, and polyphenols as shown in the phytochemical analysis of PTY-2r extract (Table 1). Thus, PTY-2r showed nephroprotective potential by reducing the oxidative stress through the restoration of antioxidant enzymes similar to other antioxidant agents like curcumin [42], resveratrol [43], berbarin [44] etc.

It has been reported that ROS-mediated oxidative stress also causes the disturbance in the balance between the pro-apoptotic (Bax) and antiapoptotic (Bcl-2) proteins, leading to an excess production of pro-apoptotic protein, which is susceptible to apoptosis [4]. The ratio of $\mathrm{Bax}$ and $\mathrm{Bcl}-2$ protein is an important factor which determines cell survivability versus cell death [45]. The increased Bax/Bcl-2 ratio may cause damage to the mitochondrial membrane integrity which induces the cytochrome c (Cyt-c) release from the mitochondrial inner membrane (MIM). The leakage of Cyt-c from MIM may lead to activation of active Caspases-3 which may further activate caspase-9 [46]. Active Caspase-3 belongs to the cysteine proteases family and is involved in various forms of apoptotic pathways. It cleaves several substrates, notably DNA repairing enzymes viz. PARP [47]. Poly (ADP) ribose polymerase (PARP) is a nuclear enzyme responsible for ribosylation of nuclear enzymes and chromosomal proteins [48]. The formation of breaks in DNA strands during apoptosis is a stimulus of activation of the PARP-1. Thus PARP-1 plays a critical role in DNA repair and apoptosis. PARP-1 is a substrate for
Caspases, particularly Caspase-3 [49]. Active Caspase-3 induced PARP-1 cleavage induces cellular disassembly, thus it acts as a specific marker for apoptosis [50]. Oxidative stress-induced apoptosis was evaluated by using the $\mathrm{Bcl}-2$ to Bax ratio, cleaved PARP, and active Caspase-3 in the kidney of DN rats. Here, we found the diminished Bcl-2 expression and increased expression of Bax, active Caspase- 3 and cleaved PARP-1 in the kidney of $\mathrm{DN}$ rats. However, the treatment with PTY-2r effectively ameliorated the changes in Bax and $\mathrm{Bcl}-2$ family proteins and inhibited the cleavage of PARP-1 and activation of Caspase-3, showed its antiapoptotic potential. The antiapoptotic property of PTY-2r could be attributed to the presence of 5-Hydroxymethylfurfural, because in literature this compound is known for its antiapoptotic potential [51, 52]. Apoptosis of podocytes is the main contributor for albuminuria [53], although we have not checked, whether podocyte specifically dying but we are anticipating that podocyte death is because of significant changes in pro-apoptotic and antiapoptotic markers in the glomerular region of the kidney of DN rats. Thus, its prevention has been shown to reduce albumin excretion. Our results also showed that PTY-2r significantly decreased the urinary albumin excretion, which is a clinical characteristic of progression of DN. Previously, there are several reports stating that antioxidants have the ability to suppress the apoptosis [54, 55]. Cell apoptosis involves ROS as a critical intermediate messenger in its signalling cascade and antioxidants are responsible for scavenging of ROS thus inhibiting apoptosis [55]. This is also confirmed by our study that the antioxidant potential of PTY-2r is not only capable of suppressing oxidative stress but also inhibits the apoptotic markers in the kidney of $\mathrm{DN}$ rats. 


\section{Conclusions}

The PTY-2r significantly retards the progression of DN in diabetic rats by attenuating oxidative stress and apoptotic markers in the kidney of STZ-induced DN rats, thus reduced urinary albumin excretion. Hence, these findings strengthen the rationale for the therapeutic use of Pueraria tuberosa in the prevention of the diabetic nephropathy.

\section{Additional files}

Additional file 1: Table S1. GCMS analysis showing chemical composition present in PTY-2r along with their structure and reported activity. Description of data- Data showing the compounds obtained from GCMS analysis and their reported activity in literature. (DOCX $280 \mathrm{~kb}$ )

\section{Abbreviations}

CAT: Catalase; DN: Diabetic nephropathy; GPx: Glutathion peroxidase; LPO: Lipid peroxidation; ROS: Reactive oxygen species; SOD: Superoxide dismutase; STZ: Streptozotocin

\section{Acknowledgements}

Authors are thankful to Department of Biotechnology, Govt. of India for financial assistance through a project. We are very grateful to Advance instrumentation research facility (AIRF), Jawaharlal Nehru University, New Delhi for GC-MS facility.

\section{Funding}

The work was solely funded by Department of Biotechnology, Govt. of India.

\section{Availability of data and materials}

The interpreted dataset of this current study is available from the corresponding authors in reasonable request.

\section{Author's contributions}

YBT, RS, \& SB designed the research. RS and SB executed the experiments. RS and $\mathrm{SB}$ conceived the experiments, interpreted the results and wrote a draft of the manuscript while YBT, RS and SB critically revised and finalized the manuscript for submission. RS \& SB equally contributed. All authors have read and approved the manuscript.

\section{Ethics approval}

The experimental procedures were approved by an animal welfare ethical committee of Institute of Medical Sciences, Banaras Hindu University, Varanasi (ethical committee letter \# No. Dean/2011-12/208). These guidelines were in accordance with the internationally accepted principles for laboratory used and care.

\section{Competing interests}

The authors declare that they have no competing interests.

\section{Publisher's Note}

Springer Nature remains neutral with regard to jurisdictional claims in published maps and institutional affiliations.

\section{Author details}

'Department of Medicinal Chemistry, Institute of Medical Sciences, Banaras Hindu University, Varanasi 221005, India. ${ }^{2}$ Department of Zoology, Institute of Science, Banaras Hindu University, Varanasi 221005, India.
Received: 16 January 2018 Accepted: 26 April 2018

Published online: 11 May 2018

\section{References}

1. Gross JL, de Azevedo MJ, Silveiro SP, Canani LH, Caramori ML, Zelmanovitz T. Diabetic nephropathy: diagnosis, prevention, and treatment. Diabetes Care. 2004;28:164-76.

2. Pan $H$, Zhang $L$, Guo M, Sui $H, L i ~ H, W u ~ W$, et al. The oxidative stress status in diabetes mellitus and diabetic nephropathy. Acta Diabetol. 2010:47:71-6.

3. Swaminathan S, Shah SV. Novel approaches targeted toward oxidative stress for the treatment of chronic kidney disease. Curr Opin Nephrol Hypertens. 2008;17:143-8.

4. Wagener FADTG, Dekker D, Berden JH, Scharstuhl A, van der Vlag J. The role of reactive oxygen species in apoptosis of the diabetic kidney. Apoptosis. 2009;14:1451-8.

5. Lee SH, Moon SJ, Paeng J, Kang HY, Nam BY, Kim S, et al. Podocyte hypertrophy precedes apoptosis under experimental diabetic conditions. Apoptosis. 2015;20:1056-71.

6. Kitamura H, Shimizu A, Masuda Y, Ishizaki M, Sugisaki Y, Yamanaka N. Apoptosis in glomerular endothelial cells during the development of glomerulosclerosis in the remnant-kidney model. Nephron Exp Nephrol Karger Publishers. 1998:6:328-36.

7. Susztak K, Raff AC, Schiffer M, Böttinger EP. Glucose-induced reactive oxygen species cause apoptosis of podocytes and podocyte depletion at the onset of diabetic nephropathy. Diabetes. 2006;55:225-33.

8. Verzola D, Gandolfo M, Ferrario F, Rastaldi M, Villaggio B, Gianiorio F, et al. Apoptosis in the kidneys of patients with type II diabetic nephropathy. Kidney Int. 2007;72(10):1262-72.

9. Toth-manikowski S, Atta MG. Diabetic kidney Disease : pathophysiology and therapeutic targets. J Diabetes Res. 2015;2015:1-16.

10. Kim H-A, Jeong K-S, Kim YK. Soy extract is more potent than genistein on tumor growth inhibition. Anticancer Res. 2015;28:2837-41.

11. Tripathi YB, Chaturvedi AP, Pandey N. Effect of Nigella sativa seeds extracts on iNOS through antioxidant potential only: crude/total extract as molecular therapy drug. Indian J Exp Biol. 2012;50:413-8.

12. CP. K. Indian Medicinal Plants - an illustrated dictionary. 1st ed. New York Springer; 2007.

13. Chatterjee B, Pancholi J. Prakriti-based medicine: A step towards personalized medicine. Ayu. Medknow publications and media Pvt. Ltd. 2011;32:141-6.

14. Maji AK, Pandit S, Banerji P, Banerjee D. Pueraria tuberosa : a review on its phytochemical and therapeutic potential. Nat Prod Res. 2014;28:2111-27.

15. Rastogi S, Katara A, Pandey MM, et al. Physical stability and HPLC analysis of Indian kudzu (Pueraria tuberosa Linn.) fortified milk. Evidence-based Complement Altern Med. 2013;6:1-6.

16. Tripathi YB, Pandey N, Yadav D, Pandey V. Anti-inflammatory effect of Pueraria tuberosa extracts through improvement in activity of red blood cell anti-oxidant enzymes. Ayu. 2013;34:297.

17. Pandey N, Chaurasia JK, Tiwari OP, Tripathi YB. Antioxidant properties of different fractions of tubers from Pueraria tuberosa Linn. Food Chem. 2007; 105:219-22.

18. Tripathi YB, Shukla R, Pandey N, Pandey V, Kumar M. An extract of Pueraria tuberosa tubers attenuates diabetic nephropathy by upregulating matrix metalloproteinase-9 expression in the kidney of diabetic rats. J Diabetes. 2017;9:123-32.

19. Srivastava $S$, Shree $P$, Pandey $H$, Tripathi YB. Incretin hormones receptor signaling plays the key role in antidiabetic potential of PTY-2 against STZinduced pancreatitis. Biomed Pharmacother. 2018;97:330-8.

20. Gupta RS, Sharma R. A review on medicinal plants exhibiting antifertility activity in males. Nat Prod Radiance. 2006:5:389-410.

21. Rao NV, Pujar B, Nimbal SK, Shantakumar SM, Satyanarayana S. Nootropic activity of tuber extract of Pueraria tuberosa (roxb). Indian J Exp Biol. 2008:46:591-8.

22. Shukla R, Pandey N, Banerjee S, Tripathi YB. Effect of extract of Pueraria tuberosa on expression of hypoxia inducible factor-1a and vascular endothelial growth factor in kidney of diabetic rats. Biomed Pharmacother. 2017;93:276-85.

23. Singleton $\mathrm{VL}$, Orthofer $\mathrm{R}$, Lamuela-Raventós RM. Analysis of total phenols and other oxidation substrates and antioxidants by means of folin-ciocalteu reagent. Methods Enzymol. 1999;299:152-78. 
24. Meda A, Lamien CE, Romito M, Millogo J, Nacoulma OG. Determination of the total phenolic, flavonoid and proline contents in Burkina Fasan honey, as well as their radical scavenging activity. Food Chem. 2005;91:571-7.

25. Van Buren JP, Robinson WB. Formation of complexes between protein and tannic acid. J Agric Food Chem. 1969;17:772-7.

26. Soetikno V, Watanabe K, Sari FR, Harima M, Thandavarayan RA, Veeraveedu PT, et al. Curcumin attenuates diabetic nephropathy by inhibiting PKC-a and PKC- $\beta 1$ activity activity in streptozotocin-induced type I diabetic rats. Mol Nutr Food Res. 2011;55:1655-65.

27. Bejma, Ramires, Ji. Free radical generation and oxidative stress with ageing and exercise: differential effects in the myocardium and liver. Acta Physiol Scand 2000;169:343-351.

28. Shahin S, Mishra V, Singh SP, Chaturvedi CM. 2.45-GHz microwave irradiation adversely affects reproductive function in male mouse, Mus musculus by inducing oxidative and nitrosative stress. Free Radic Res. 2014; 48:511-25.

29. Ohkawa H, Ohishi N, Yagi K. Assay for lipid peroxides in animal tissues by thiobarbituric acid reaction. Anal Biochem. 1979;95:351-8.

30. Beauchamp C, Fridovich I. Superoxide dismutase: improved assays and an assay applicable to acrylamide gels. Anal Biochem. 1971;44:276-87.

31. Catalase AH. In: methods in enzymatic analysis. 2nd ed. New York: Bergmeyer HU, Academic Press; 1974.

32. Mantha SV, Prasad M, Kalra J, Prasad K. Antioxidant enzymes in hypercholesterolemia and effects of vitamin $\mathrm{E}$ in rabbits. Atherosclerosis. 1993;101:135-44

33. Nagwani S, Tripathi YB. Amelioration of cisplatin induced nephrotoxicity by PTY: a herbal preparation. Food Chem Toxicol. 2010:48:2253-8.

34. Tripathi YB, Pandey N, Tripathi D, Tripathi P. Oily fraction of Semecarpus anacardium Linn nuts involves protein kinase $C$ activation for its proinflammatory response. Indian J Exp Biol. 2010:48:1204-9.

35. Banerjee S, Tsutsui K, Chaturvedi CM. Apoptosis-mediated testicular alteration in Japanese quail ( Coturnix coturnix japonica ) in response to temporal phase relation of serotonergic and dopaminergic oscillations. J Exp Biol. 2016;219:1476-87

36. Singh DK, Winocour P, Farrington K. Oxidative stress in early diabetic nephropathy: fueling the fire. Nat Rev Endocrinol. 2011;7:176-84.

37. Kashihara N, Haruna Y, Kondeti VK, Kanwar YS. Oxidative stress in diabetic nephropathy. Curr Med Chem. 2010;17:4256-69.

38. Forbes JM, Coughlan MT, Cooper ME. Oxidative stress as a major culprit in kidney disease in diabetes. Diabetes. 2008;57:1446-54.

39. Palm F, Nordquist L, Wilcox CS, Hansell P. Oxidative Stress and Hypoxia in the Pathogenesis of Diabetic Nephropathy; 2011. p. 559-86.

40. Giribabu N, Rao PV, Kumar KP, Muniandy S, Swapna Rekha S, Salleh N. Aqueous extract of Phyllanthus niruri leaves displays in vitro antioxidant activity and prevents the elevation of oxidative stress in the kidney of Streptozotocin-induced diabetic male rats. Evidence-Based Complement Altern Med. 2014;2014:1-10.

41. Yu X, Zhao M, Liu F, Zeng S, Hu J. Identification of 2,3-dihydro-3,5dihydroxy-6-methyl-4H-pyran-4-one as a strong antioxidant in glucosehistidine Maillard reaction products. Food Res Int. 2013;51:397-403.

42. Trujillo J, Chirino Yl, Molina-Jijón E, Andérica-Romero AC, Tapia E, PedrazaChaverrí J. Renoprotective effect of the antioxidant curcumin: recent findings. Redox Biol. 2013;1:448-56.

43. Gülçin I. Antioxidant properties of resveratrol: a structure-activity insight. Innov Food Sci Emerg Technol. 2010;11:210-8.

44. Pongkittiphan V, Chavasiri W, Supabphol R. Antioxidant effect of Berberine and its phenolic derivatives against human Fibrosarcoma cells. Asian Pac J Cancer Prev. 2015;16:5371-6.

45. Oltvai ZN, Milliman CL, Korsmeyer SJ. BCl-2 heterodimerizes in vivo with a conserved homolog, Bax, that accelerates programmed cell death. Cell. 1993;74:609-19.

46. Desagher S, Martinou JC. Mitochondria as the central control point of apoptosis. Trends Cell Biol. 2000;10:369-77.

47. Nuñez G, Benedict MA, Hu Y, Inohara N. Caspases: the proteases of the apoptotic pathway. Oncogene. 1998;17:3237-45

48. Ohashi Y, Ueda K, Kawaichi M, Hayaishi O. Activation of DNA ligase by poly(ADP-ribose) in chromatin. Proc Natl Acad Sci U S A. 1983;80:3604-7.

49. Tewari M, Quan LT, O'Rourke K, Desnoyers S, Zeng Z, Beidler DR, et al. Yama/CPP32 beta, a mammalian homolog of CED-3, is a CrmA-inhibitable protease that cleaves the death substrate poly(ADP-ribose) polymerase. Cell. 1995;81:801-9.
50. Chaitanya GV, Steven AJ, Babu PP. PARP-1 cleavage fragments: signatures of cell-death proteases in neurodegeneration. Cell Commun. Signal. BioMed Central. 2010;8:31

51. Gu H, Jiang $Y-B$, Jiang H-Y, Xu D-Q, Yu J-T, Ding $X$, et al. Effect of 5hydroxymethyl furfural on $\mathrm{BCL}-2$ and NF-kappaB gene expression of apoptotic rat hippocampal neurons injured by H2O2. J Chinese Med Mater. 2011;34:1753-6.

52. Gu H, Jiang Z, Wang $M$, Jiang $H$, Zhao F. Ding $X$, et al. 5Hydroxymethylfurfural from wine-processed Fructus corni inhibits hippocampal neuron apoptosis. Neural Regen Res. 2013;8:2605-14.

53. Zhou L, An X-F, Teng S-C, Liu J-S, Shang W-B, Zhang A-H, et al. Pretreatment with the Total flavone glycosides of Flos Abelmoschus manihot and Hyperoside prevents glomerular podocyte apoptosis in Streptozotocin-induced diabetic nephropathy. J Med Food. 2012;15:461-8.

54. Kahl R, Kampkötter A, Wätjen W, Chovolou Y. Antioxidant enzymes and apoptosis. Drug Metab Rev. 2004;36:747-62.

55. Zeisel SH. Antioxidants suppress apoptosis. J Nutr. 2004;134:3179S-80S.

56. Ban JO, Hwang IG, Kim TM, Hwang BY, Lee US, Jeong H-S, et al. Antiproliferate and pro-apoptotic effects of 2,3-dihydro-3,5-dihydroxy-6-methyl$4 \mathrm{H}$-pyranone through inactivation of NF-KB in human Colon Cancer cells. Arch Pharm Res. 2007;30:1455-63.

57. Hadi Hameed I, - J, Al MJ, jihadi Mohammed G. Anti-bacterial, antifungal activity and chemical analysis of Punica grantanum (pomegranate peel) using GC-MS and FTIR spectroscopy * 3. Int J Pharmacogn Phytochem Res 2016;8:480-494

58. Zhong-Hui $P$, Zhang $Y-Q$, Zhong-Qiong $Y$, Jiao $X$, Ren-Yong J, Yang $L$, et al. Antibacterial activity of 9-Octadecanoic acid-Hexadecanoic acidTetrahydrofuran-3,4-Diyl Ester from neem oil. Agric Sci China. 2010;9:123640.

59. Aparna V, Dileep KV, Mandal PK, Karthe P, Sadasivan C, Haridas M. Antiinflammatory property of n-Hexadecanoic acid: structural evidence and kinetic assessment. Chem Biol Drug Des. 2012;80:434-9.

60. Yoo Y-C, Shin B-H, Hong J-H, Lee J, Chee H-Y, Song K-S, et al. Isolation of fatty acids with anticancer activity from Protaetia brevitarsis larva. Arch Pharm Res. 2007:30:361-5.

\section{Ready to submit your research? Choose BMC and benefit from:}

- fast, convenient online submission

- thorough peer review by experienced researchers in your field

- rapid publication on acceptance

- support for research data, including large and complex data types

- gold Open Access which fosters wider collaboration and increased citations

- maximum visibility for your research: over $100 \mathrm{M}$ website views per year

At BMC, research is always in progress.

Learn more biomedcentral.com/submissions 